\title{
Rebooting a failed promise of climate finance
}

\author{
The 2009 pledge to mobilize US\$100 billion a year by 2020 in climate finance to developing nations was not \\ specific on what types of funding could count. Indeterminacy and questionable claims make it impossible to know \\ if developed nations have delivered; as 2020 passes, opportunity exists to address these failures in a new pledge.
}

\section{J. Timmons Roberts, Romain Weikmans, Stacy-ann Robinson, David Ciplet, Mizan Khan and Danielle Falzon}

A $\mathrm{t}$ the 2009 Copenhagen climate negotiations, lagging action by the world's wealthier nations on reducing emissions led developing countries to threaten to walk out. Their demand was a major promise of funding to help them cope with climate impacts and to do the work of reducing or avoiding emissions ${ }^{1}$. In response, developed nations committed to provide "scaled up, new and additional, predictable and adequate funding" to meet "a goal of mobilizing jointly US $\$ 100$ billion per year by 2020 to address the needs of developing countries"2. However, this US $\$ 100$ billion per year climate finance promise had deep flaws, making it impossible to now assess whether it has been met. The original pledge stated that "this funding will come from a wide variety of sources, public and private, bilateral and multilateral, including alternative sources of finance" ${ }^{2}$, but specified no rules on what could be counted in those categories. As we embark upon a pivotal decade ahead for climate change, there is opportunity to take stock of what has come to pass since Copenhagen on climate finance and develop a functional post-2020 model.

\section{Accounting differently}

In the absence of clearly established accounting rules under the United Nations Framework Convention on Climate Change (UNFCCC), each developed country has been able to decide what it reports as 'climate finance's. In November 2020, the Organisation for Economic Co-operation and Development (OECD), a club of mostly rich countries, released a report stating that climate finance reached US $\$ 78.9$ billion in 2018 ( ref. $^{4}$ ). But there is widespread scepticism about these numbers. Previous OECD reports have been poorly received or simply rejected by developing country representatives, charities and academic observers $^{3}$. The OECD itself acknowledges that "significant inconsistencies in terms of methodologies, categorizations and definitions adopted across countries" exist

Table 1 | Four conflicting sets of estimates on public climate finance from developed to developing countries

\begin{tabular}{lllllll} 
Data source & $\mathbf{2 0 1 3}$ & $\mathbf{2 0 1 4}$ & $\mathbf{2 0 1 5}$ & $\mathbf{2 0 1 6}$ & $\mathbf{2 0 1 7}$ & $\mathbf{2 0 1 8}$ \\
\hline OECD $^{4}$ & 37.9 & 43.5 & 42.1 & 46.9 & 54.5 & 62.2 \\
Biennial reports to UNFCCC $^{7}$ & 25.4 & 26.6 & 33 & 37.5 & NA & NA \\
Oxfam $^{6}$ & & $11-21^{\text {a }}$ & & $15-19.5^{\mathrm{a}}$ & & $19-22.5^{\mathrm{a}}$ \\
Indian Finance Ministry $^{5}$ & $1-2.2^{\mathrm{a}}$ & $\mathrm{NA}$ & $\mathrm{NA}$ & $\mathrm{NA}$ & NA & \\
\hline
\end{tabular}

All figures in US $\$$ billion. Due to time lags in official reporting, data on 2019 and 2020 flows will only be available in 2022. ${ }^{2}$ Yearly average. NA, not applicable.

in developed countries' official reporting to the UNFCCC ${ }^{4}$. The resulting multitude of accounting approaches has led to widely contrasting reports on total public climate finance that has been provided annually (Table 1). Statements on private climate finance mobilized by developed countries in poor countries are even more contested.

Views on OECD and UNFCCC collations of claims by developed nations have conflicted glaringly. For example, in 2013-2014, the OECD claimed an annual average of US $\$ 57$ billion of total public and private climate finance, while the Indian Ministry of Finance pointed to loopholes in their methodology and asserted that only US $\$ 1-2.2$ billion should be counted ${ }^{5}$. In contrast to the recent OECD 2020 report, Oxfam estimated only US\$19-22.5 billion in public finance specifically targeting climate action from 2017-2018, a third of what was reported by developed countries ${ }^{6}$.

The huge differences in numbers are mostly linked to three issues (Fig. 1). First, most developed countries count all financial instruments (loans, grants, investments, insurance) at face value in their reporting to the UNFCCC ${ }^{7,8}$. This means that a US $\$ 50$ million loan appears equal to a grant of US\$50 million in spite of the fact that US\$60 million or more might have to be repaid on even 'concessional loans' (that is, loans that are extended on terms more generous than market loans), and such repayments would not be counted against the original flows ${ }^{5,6}$.
Second, bilateral and multilateral funding flows have been screened by completely different methods for whether they target climate objectives and should therefore count towards the annual US $\$ 100$ billion per year pledge. The OECD Rio Marker system, where governments self-categorize their projects as either 'principally' or 'significantly' climate-related', was especially problematic. These Rio Markers for climate change mitigation and adaptation have been refined over the years but were often unevenly applied by donors ${ }^{9}$. Each member nation continues to use a different factor by which they scale the amount of a project they count if a project just lists climate as one aim, versus being its principal objective - these vary from $0 \%$ all the way to $100 \%$, Meanwhile, multilateral development banks developed their own categorization system ${ }^{10}$, and accounting methodologies used by some countries have changed over time, complicating any assessment of trends.

Third, the long-standing issue of whether funds are 'new and additional', as has been promised since 1992, has not been resolved. The diversion of development assistance, which was previously used for education and health to areas that count as climate finance, for example, would be funding reallocated rather than increased. Substantial controversies persist on the issue.

\section{Managing the funds}

The funds promised in Copenhagen were expected by developing countries to be 


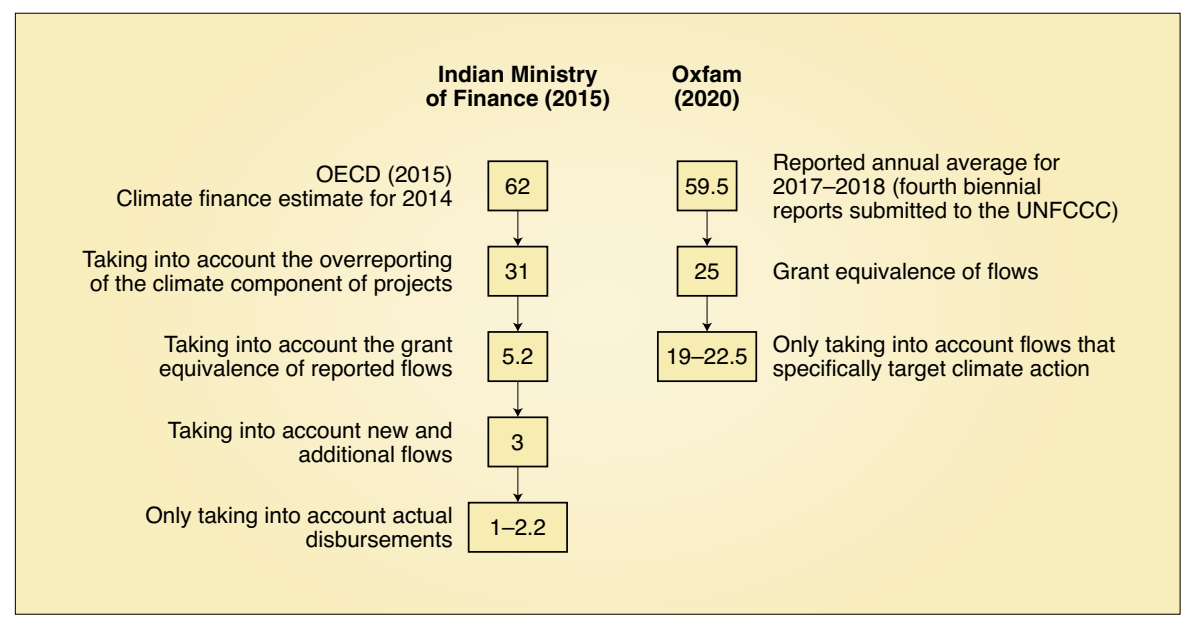

Fig. 1| Two examples of scaling down of OECD climate finance estimates. Values indicate billions of total US\$ estimated to be actually flowing from developed nations to developing nations.

dominated by public grants directed through the then new UNFCCC Green Climate Fund $^{1,11}$. There, those nations would have their own representatives empowered to help decide the direction of these flows, and they could be better coordinated and targeted. What ensued is quite the opposite: climate funds are funnelled through over 100 channels, very few of which are controlled in meaningful ways by developing nations ${ }^{3}$. These include developed countries' aid and export promotion agencies, private banks, equity funds and corporations, and lending and granting arms of multilateral institutions like the World Bank and regional banks. There are several United Nations (UN) agencies supporting climate action, including the UN Environment and Development Programmes and the Global Environment Facility, but these are chronically underfunded and require pledges to be 'replenished' regularly by contributor governments facing other demands on their federal budgets. This makes funding insecure and future planning difficult. Developing countries thus often have limited decision-making power over their own climate and development planning, and the fragmented institutional architecture has inevitable consequences for transparency, accountability and effectiveness of climate finance ${ }^{3,12}$.

Negotiations since Copenhagen have also been characterized by a growing focus on how to effectively increase private sector engagement in climate change through financial investments ${ }^{3}$. This raises questions about what types of private finance can be said to have been mobilized by developed countries, as was promised. The OECD now estimates that private climate finance has been stagnating, at US $\$ 16.7$ billion in 2014,
US $\$ 10.1$ billion in 2016 and US $\$ 14.6$ billion in 2018 (ref. ${ }^{4}$ ). The COVID-19 pandemic has further reduced climate finance delivery ${ }^{13,14}$; thus, this trend will continue or may worsen. There is no centralized body with the capability to ensure that private finance reaches countries most in need, or responds effectively to priorities such as climate adaptation and damages beyond repair ('loss and damage') ${ }^{6,11}$. The recent OECD report reveals that in fact only $3 \%$ of mobilized private finance is helping poor countries adapt to climate impacts ${ }^{4,15}$. Rather, and as widely foreseen, private investments go where money is to be made or emissions reductions can be counted.

\section{Looking ahead}

In December 2020, a group of experts mandated by the UN Secretary General concluded that the US\$100 billion goal would likely not be met in 2020 , even by developed countries' accounting standards ${ }^{14}$. Final official data on 2020 flows is expected in 2022, but if this failure is confirmed, it will likely lead to further erosion of trust between developed and developing countries - precisely the gap the Copenhagen promise sought to bridge. Of the claimed climate finance flows so far, only about $20 \%$ has targeted adaptation - the rest went to greenhouse gas mitigation projects. In addition to needing more low-carbon technologies to support clean energy and land-use transitions, more funds should flow to projects addressing vulnerability due to escalating climate impacts and building broader resilience.

Developed countries continue to avoid fundamental accountability issues by taking advantage of ambiguous technicalities in reporting standards. This suggests profound failings of procedural as well as distributive justice ${ }^{1}$. These failures could be addressed with major improvements in accountability to establish clearer and more rigorous rules of what nations can count as climate finance ${ }^{3,6}$. The fragmented climate finance system needs coordination and strategic targeting of support to areas and nations most in need, in line with their domestic priorities.

The 2015 Paris Agreement specified that a new collective, quantified goal for climate finance is to be agreed prior to 2025 , with US $\$ 100$ billion per year as the minimum. Now is the time to begin that effort with ambition and accountability to build enduring trust and resilience. Future climate finance pledges and targets should be based on realistic assessments of developing countries' needs. Then real plans must be built and implemented to meet those funding targets; for example, through innovative finance, like levies on international airline passengers and bunker fuels. To meet the promise of adequate and predictable' financing made back in Copenhagen, new global financing mechanisms have to be implemented, since annually decided 'contributions' from national treasuries are not delivering on the promise. First though, clear rules for what counts as climate finance need to be agreed.

\section{J. Timmons Roberts (D) 1 , Romain Weikmans (D) 2 Stacy-ann Robinson (D) ${ }^{3}$, David Ciplet $^{4}$, Mizan Khan ${ }^{5}$ and Danielle Falzon ${ }^{6}$ ${ }^{1}$ Institute at Brown for Environment and Society, Brown University, Providence, RI, USA. ${ }^{2}$ Department of Geosciences, Environment and Society, Université Libre de Bruxelles, Brussels, Belgium. ${ }^{3}$ Environmental Studies Program, Colby College, Waterville, $M E$, USA. ${ }^{4}$ Environmental Studies Program, University of Colorado Boulder, Boulder, CO, USA. ${ }^{5}$ International Centre for Climate Change and Development (ICCCAD), Dhaka, Bangladesh. ${ }^{6}$ Department of Sociology, Brown University, Providence, RI, USA.

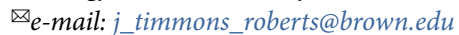

Published online: 18 February 2021 https://doi.org/10.1038/s41558-021-00990-2

References

1. Ciplet, D., Roberts, J. T. \& Khan, M. Power in a Warming World: The New Global Politics of Climate Change and The Remaking of Environmental Inequality (MIT Press, 2015).

2. Copenhagen Accord (UNFCCC, 2009); https://unfccc.int/ resource/docs/2009/cop15/eng/107.pdf

3. Weikmans, R. \& Roberts, J. T. Clim. Dev. 11, 97-111 (2019).

4. Climate Finance Provided and Mobilised by Developed Countries in 2013-18 (OECD Publishing, 2020); https://doi.org/10.1787/ f0773d 55 -en

5. Climate Finance, Analysis of a Recent OECD Report: Some Credible Facts Needed (Indian Ministry of Finance, 2015); https://bit.ly/3o08LsV

6. Climate Finance Shadow Report 2020: Assessing Progress Towards the $\$ 100$ Billion Commitment (Oxfam, 2020); https://bit.ly/3qLQLV9 
7. Compilation and Synthesis of Third Biennial Reports of Parties Included in Annex I to the Convention (UNFCCC, 2018); https:// unfccc.int/sites/default/files/resource/inf8.pdf

8. Climate Finance in 2013-14 and the USD 100 Billion Goal (OECD Publishing, 2015); https://doi.org/10.1787/9789264249424-en

9. Results of the First Survey on Coefficients that Members Apply to the Rio Marker Data When Reporting to the UN Conventions on Climate Change and Biodiversity (OECD Development Co-operation Directorate, 2019); https://bit.ly/3bTBrS8
10. Joint Report on Multilateral Development Banks' Climate Finance (Multilateral Development Banks, 2016); https://bit.ly/3isETEq

11. Khan, M., Robinson, S., Weikmans, R., Ciplet, D. \& Roberts, J. T. Climatic Change 161, 251-269 (2020).

12. Ciplet, D., Adams, K. M., Weikmans, R. \& Roberts, J. T. Glob. Environ. Polit. 18, 130-150 (2018).

13. Yeo, S. Nature 573, 328-331 (2019).

14. Delivering on the $\$ 100$ Billion Climate Finance Commitment and Transforming Climate Finance (The Independent
Expert Group on Climate Finance, 2020); https://www.un. org/sites/un2.un.org/files/100_billion_climate_finance report.pdf

15. Robinson, S. \& Dornan, M. Reg. Environ. Change 17, 1103-1115 (2017)

Competing interests

The authors declare no competing interests.

\section{nature} podcast

\section{The week's best science, from the world's leading science journal.}

\section{NATURE.COM/NATURE/PODCAST}

